\title{
A IMPLEMENTAÇÃO DA EDUCAÇÃO A DISTÂNCIA NO SISTEMA PENITENCIÁRIO: EFETIVAÇÃO DOS DIREITOS FUNDAMENTAIS E RECONHECIMENTO DA DIGNIDADE HUMANA DO APENADO
}

\author{
THE IMPLEMENTATION OF DISTANCE EDUCATION IN THE PENITENTIARY \\ SYSTEM: EFFECTIVENESS OF FUNDAMENTAL LAW AND RECOGNITION OF THE \\ HUMAN DIGNITY OF THE PRISIONER
}

Ivan Dias da Motta

\begin{abstract}
Professor Permanente do Programa de Mestrado em Ciências Jurídicas pelo Centro Universitário de Maringá UNICESUMAR. Possui graduação em Direito pela Universidade Estadual de Maringá (1996), mestrado em Direito das Relações Sociais pela Pontifícia Universidade Católica de São Paulo (1998) e doutorado em Direito das Relações Sociais pela Pontifícia Universidade Católica de São Paulo (2000),

Pós-doutorado em Direito Educacional pela Pontifícia Universidade Católica de São Paulo (2001).

Possui atuação profissional na área da advocacia e consultoria em Direito Educacional.

Email: ivan.iddm@gmail.com
\end{abstract}

Thiene Nogueira Sela

Mestre pelo Programa de Pós-Graduação em Ciências Jurídicas do Centro Universitário Cesumar de Maringá UNICESUMAR. Especialista em Direito Penal e Processo Penal pela Universidade Estadual de Londrina (2007). Graduada em Direito pela Universidade Norte do Paraná (2004). Advogada.

E-mail: thiene.sella@hotmail.com

Recebido em: 04/10/2018

Aprovado em: 14/01/2019

RESUMO: O presente artigo reporta sobre o direito à educação à distância aos apenados que estejam cumprindo pena no sistema penitenciário, como forma de reconhecimento da dignidade humana do ser encarcerado e uma proposta de efetivação de seus direitos fundamentais e da personalidade. A educação é um instrumento de liberdade e integra o núcleo essencial dos direitos que conduzem à cidadania. É possível afirmar que se trata de direito fundamental, necessário à formação do ser humano, inserido no conteúdo do mínimo existencial, e, portanto, aspecto fundamental à dignificação humana e à ressocialização do apenado. O objetivo deste estudo é analisar, através do método hipotético-dedutivo, que a educação, na modalidade à distância, proporciona a democratização do acesso à informação, à cultura, à formação e, consequentemente, às condições mais dignas de vida ao encarcerado. Assim, se comprovará que a educação se trata de um elemento caracterizador do mínimo existencial e o seu exercício não pode ser postergado, necessitando da atuação prioritária e efetiva do Estado. A principal forma de atuação estatal é por intermédio das políticas públicas, que, nesta pesquisa, configuram-se nas políticas públicas educacionais de promoção humana.

Palavras-chave: Apenado. Dignidade Humana. Direito à Educação. Direito Fundamental. Educação à Distância.

ABSTRACT: This article deals with the law to distance education for the prisoners who are serving their sentences in the penitentiary system, as a way of recognizing the human dignity of being imprisoned and a proposal for the realization of their fundamental rights and personality. Education is an instrument of freedom and is part of the core of the rights that lead to citizenship. It is possible to affirm that it is a fundamental right, necessary for the formation of the human being, 
inserted in the content of the existential minimum, and, therefore, fundamental aspect to the human dignification and the resocialization of the distressed one. Education, in the distance mode, provides the democratization of access to information, culture, training and, consequently, the most worthy conditions of life for the incarcerated. Since education is an element that characterizes the existential minimum, its exercise can not be postponed, necessitating the priority and effective action of the State. The main form of state action is through public policies, which, in this research, are configured in the public educational policies of human promotion.

Key words: Prisioner. Human Dignity. Education Law. Fundamental Law. Distance Education.

\section{INTRODUÇÃO}

A solução para a questão da crise do sistema penitenciário está longe de ser alcançada. Contudo, através das iniciativas, discussões e pautando-se no princípio constitucional da dignidade da pessoa humana, que há possibilidade efetiva de ressocialização do indivíduo através direito à educação, na modalidade à distância, ofertado no próprio estabelecimento prisional em que se cumpre a pena.

É certo que a execução da pena tem como objetivo primordial a punição daquele indivíduo que cometeu um delito, como também evitar a reincidência e possibilitar sua reinserção em sociedade. Nesse contexto, demonstrar-se-á a realidade vivenciada dentro dos presídios, fruto da crise que se instalou na estrutura do sistema penitenciário brasileiro, enraizada pelo colapso moral dos indivíduos que compõem a sistemática carcerária.

Num primeiro momento se evidência, de maneira breve, algumas considerações pertinentes acerca do princípio da dignidade da pessoa humana, haja vista que dignidade consiste em garantir condições adequadas e justas de sobrevivência e recuperação dos apenados. Sem dignidade o indivíduo estaria renunciando a sua própria, e com isso ela estaria sendo graduada, constituindo-se numa total contradição.

Demonstrar-se-á que se a dignidade da pessoa humana é fundamento do Estado brasileiro, a prevalência do indivíduo deve ser critério norteador e vinculante da lei, a fím de que seja alcançado o objetivo de pleno desenvolvimento de cada um dos integrantes desse modelo estatal.

Por conseguinte, em breve contexto será arguida a situação atual de falência do sistema penitenciário brasileiro, pois sequer são asseguradas condições mínimas de sobrevivência aos apenados, sendo a integridade, a intimidade e a identidade de cada presidiário tratadas como objetos de ingerência negligente do Estado, o qual nem mesmo abarca condições estruturais para executar os ditames da Lei de Execução Penal e o benefício da remição nela inserido.

Diante deste contingente, nada mais plausivel que o Estado tenha alternativas para se redimir e que implemente políticas de promoção humana no sistema carcerário e reconheça o direito à educação dos apenados com previsão na Lei de Execução Penal.

Na sequência será explicitado que a Constituição Federal de 1988 traz diversas previsões sobre o referido direito à educação, apontando, de forma expressa, como: direito social (artigo $6^{\circ}$ ), impondo, assim, uma prestação efetiva por parte do Estado, e, como direito público subjetivo (artigo 208, $\S 1^{\circ}$ ). O direito à educação, igualmente, pode ser analisado como direito da personalidade, uma vez que é elemento necessário ao pleno desenvolvimento da pessoa humana (conforme previsão do artigo 205, da Constituição Federal e artigo $3^{\circ}$, da Lei 9.394/96), integrando o mínimo existencial.

O direito a educação, como objeto integrante do mínimo existencial, deve ser assegurado pelo Estado, sendo necessária não apenas para a formação da personalidade e dignificação do indivíduo em si considerado, mas também para sua recuperação e atuação na e perante a sociedade, como, por exemplo, através do exercício da cidadania e também na qualificação para o mercado de trabalho. 
Necessário delimitar que o objeto de estudo que é a educação a distância, a qual vem propiciar a inclusão e o acesso ao ensino à população carcerária, contribuindo para a reeducação social, ética e oportunizar a reinserção social dos apenados atualmente privados de sua liberdade, que por vezes nem tiveram acesso à educação básica.

Por fim será abordado o contexto de atuação do Estado que se dá por intermédio das políticas públicas, que, no caso em comento, podem ser consideradas políticas públicas de promoção humana, já que podem visar o pleno desenvolvimento do individuo apenado e fornecer elementos necessários para que o mesmo resgate sua dignidade, exerça seus direitos correlatos e se ressocialize.

A metodologia utilizada neste texto será hipotético-dedutivo, além de consulta bibliográfica, análise de doutrina e legislação brasileira. Tal metodologia visa embasar a hipótese fundante da temática apresentada.

\section{O PRINCÍPIO DA DIGNIDADE DA PESSOA DO APENADO E O SISTEMA PENITENCIÁRIO}

Quando se busca a compreensão do significado de dignidade da pessoa humana, o qual vem expressamente consagrado na Constituição Federal de 1988, oportuno se valer da lição de Paulo Bonavides:

A dignidade da pessoa humana desde muito deixou de ser exclusiva manifestação conceitual daquele direito natural metapositivo, cuja essência se buscava ora na razão divina ora na razão humana, consoante professavam em suas lições de teologia e filosofia os pensadores dos períodos clássico e medievo, para se converter, de último, numa proposição autônoma, do mais súbito teor axiológico, irremissivelmente presa à concretização constitucional dos direitos fundamentais ${ }^{1}$.

O princípio da dignidade da pessoa humana é expressamente enunciado no artigo $1^{\circ}$, inciso III da Constituição Federal de 1988, objeto de previsão no texto constitucional pátrio como lei fundamental, dessa maneira não contém apenas declarações de cunho moral e ético. Refuta-se que a moral é um princípio supremo como imperativo categórico, ou seja, uma ação necessária em si mesma $^{2}$.

E em consequência disso, esse estudo baseia-se na análise do princípio da dignidade da pessoa humana, e na função norteadora de cunho interpretativo eminentemente constitucional, o qual é um dos pilares do Estado Democrático de Direito, em face do seu estabelecimento na Carta Magna o faz in locu hermenêutico na interpretação do dispositivo legal, visto que no modelo jurídico vigente no Estado, faz-se necessária à interpretação do texto maior, observando sempre tal regramento, ou seja, o fundamento do Estado Brasileiro ${ }^{3}$.

Os princípios constitucionais são valorados como "vigas mestras" do ordenamento jurídico e segundo ensinamentos de Rui Samuel Espíndola:

(...) além de servirem como parâmetro para solução de problemas jurídicos que exijam a sua aplicação normativa, ainda funcionam como critérios interpretativos para solução de outros casos, que não lhes solicitem, diretamente, aplicação jurídica. Esses casos podem ter em mira tanto normas constitucionais quanto infraconstitucionais. Ou seja, os princípios constitucionais, além de desempenharem a função de normas com diferentes

\footnotetext{
${ }^{1}$ BONAVIDES, Paulo. Curso de Direito Constitucional. 31. ed. São Paulo: Malheiros, 2016.

${ }^{2}$ MORAES, Alexandre. Constituição do Brasil Interpretação e Legislação Constitucional. São Paulo: Jurídico Atlas, 2003.

${ }^{3}$ MORAES, Alexandre. Constituição do Brasil Interpretação e Legislação Constitucional. São Paulo: Jurídico Atlas, 2003.
} 
graus de concretização, ainda funcionam como critério para interpretação de outras normas, não importando o nível hierárquico-normativo dessas ${ }^{4}$.

Por isso que é o princípio constitucional de maior hierarquia axiológica valorativa e expressa um valor guia para todo o ordenamento jurídico. Ademais, por ser um princípio de suma importância, é de difícil conceituação, vez que possui entornos vagos e imprecisos.

Nas palavras do professor Ingo Sarlet, o princípio da dignidade da pessoa humana:

(...) é a qualidade intrínseca e distintiva da cada ser humano que o faz merecedor do mesmo respeito e consideração por parte do Estado e da comunidade, implicando, neste sentido, um complexo de direitos e deveres fundamentais que assegurem a pessoa tanto contra todo e qualquer ato de cunho degradante e desumano, como venham a lhe garantir as condições existenciais mínimas para uma vida saudável, alem de propiciar e promover sua participação ativa e corresponsável nos destinos da própria existência e da vida em comunhão com os demais seres humanos ${ }^{5}$.

Ressalta-se com a finalidade de breve compreensão do significado do magno princípio que se discorre, considerações acerca de sua eficácia jurídica, em função de tratar-se de direito fundamental autêntico e autônomo, sendo referência de aplicação e de interpretação, possuindo íntimo vínculo com os direitos fundamentais.

Os direitos à vida, à liberdade e à igualdade são exigências basilares da dignidade da pessoa humana, exemplo disso, é que o fundamento do texto constitucional sempre confirma tal princípio. Assim, toda a atividade do Estado encontra-se vinculada ao princípio da dignidade da pessoa humana, porque se impõe como premissa o dever de respeito e de proteção ao ser humano, tendo como característica a obrigação estatal de abster-se de ingerências individuais, bem como no seu dever de proteger contra agressões de terceiros. Logo, são, ao mesmo tempo, limite e tarefa estatal ${ }^{6}$.

Ademais, cabe ao Estado guiar as ações para preservar a dignidade existente, e criar condições que possibilitem o pleno exercício dela. Mesmo porque, a dignidade é qualidade intrínseca do indivíduo, o qual simplesmente existe, nesse sentido é irrenunciável e inalienável. E, ainda, qualifica o ser humano, reconhecendo o respeito e a proteção, logo, é inerente à pessoa ${ }^{7}$.

Em função disso, por mais grave que o delito seja, bem como sua consequência, o indivíduo deve pagar estritamente por sua culpa, não perdendo dessa maneira sua condição de pessoa, porque com tal tratamento busca-se a inadmissível consideração do cárcere como referência de marcação ou redução do indivíduo à condição de marginal perpétuo ${ }^{8}$.

As penas privativas de liberdade atravessam inúmeras dificuldades em seu contexto executor, haja vista a problemática da superlotação. Portanto, operadores do direito devem, numa ação conjunta ao Estado, empreender enormes esforços na tentativa de se lograr alternativas viáveis para o colapso do sistema carcerário vigente ${ }^{9}$. E a via que se defende nessa pesquisa é a ressocialização do apenado através do direito à educação.

É passível de se perceber a contradição entre o princípio da dignidade da pessoa humana e o sistema penitenciário brasileiro. Não há o mínimo respeito pela vida dos encarcerados, uma vez que os presídios se encontram falidos, pois as mínimas condições de sobrevivência não são

\footnotetext{
${ }^{4}$ ESPÍNDOLA, Rui Samuel. Conceito de Princípios Constitucionais. 2. ed. São Paulo: Revista dos Tribunais, 2002.

${ }^{5}$ SARLET, Ingo Wolfgang. Dignidade da Pessoa Humana e Direitos Fundamentais na Constituição de 1988. Porto Alegre: Livraria do Advogado, 2001.

${ }^{6}$ BARROSO, Luís Roberto. A dignidade da pessoa humana no direito constitucional contemporâneo: a construção de um conceito jurídico à luz da jurisprudência mundial. Tradução Humberto Laport de Mello. $3^{\mathrm{a}}$ reimpressão. Belo Horizonte: Fórum, 2014.

${ }^{7}$ BARROSO, Luís Roberto. A dignidade da pessoa humana no direito constitucional contemporâneo: a construção de um conceito jurídico à luz da jurisprudência mundial. Tradução Humberto Laport de Mello. $3^{\text {a }}$ reimpressão. Belo Horizonte: Fórum, 2014.

${ }^{8}$ BECCARIA, Cesare. Dos Delitos e Das Penas. São Paulo: Martin Claret, 2003.

${ }^{9}$ BITENCOURT, Cezar Roberto. Tratado de Direito Penal - Parte Geral. 9. ed. São Paulo: Saraiva, 2004. Revista de Direito Brasileira | São Paulo, SP | v. 21 | n. 8 | p.6-21 |Set./Dez. 2018
} 
asseguradas, e assim a integridade, a intimidade e a identidade de cada um dos apenados são tratadas como objetos de ingerência negligente do Estado ${ }^{10}$.

Quanto ao plano sociológico da questão, o cárcere é fator criminógeno na maioria dos casos, porque a realidade de sua aplicação nega o plano teórico. Trata-se de uma espécie de seletividade da justiça, pois os atingidos são as pessoas que pertencem às camadas sociais menos favorecidas financeira e intelectualmente, os menos aptos para a competição imposta pela sociedade capitalista, isso é repugnante ${ }^{11}$.

Importante confessar que a realidade da população carcerária, por mais que se pretenda com a imposição do cumprimento das penas prepará-la para a vida livre, certamente, o ambiente em nada propicia o alcance deste resultado, mas sim fomenta a veia criminosa ${ }^{12}$.

Os apenados são tratados como homens objetos, e com isso tornam-se antíteses da noção do princípio da dignidade da pessoa humana. Insurge-se dessa forma o seguinte questionamento: até que ponto a dignidade é possível?

Pois bem, difundir a tendência de uma corrente de aplicação de penas mais curtas, e no que concerne ao cumprimento de penas mais gravosas uma tecnicização dos estabelecimentos prisionais, tornando os apenados indivíduos produtivos e intelectuais, dignos de um retorno à sociedade, sem a mácula da marginalização, efetivando-se assim a tão aspirada sociedade pluralista, a qual irá respeitar os indivíduos e concretizar o tão exaltado princípio da dignidade da pessoa humana ${ }^{13}$.

\section{A LEI DE EXECUÇÃO PENAL: BENEFÍCIO DA REMIÇÃO ATRAVÉS DO DIREITO À EDUCAÇÃ̃O}

A Lei de Execução Penal destaca que o estudo e o trabalho exercidos pelo apenado são direitos, mas também deveres, visto que cumprem tanto com as funções educativas quanto produtivas.

O trabalho e o estudo, como direitos, possibilitam ao apenado incluí-lo no sistema progressivo de cumprimento da pena. Já no âmbito do dever, trabalho e estudo se caracterizam como importante função que possibilita a reinserção do indivíduo no contexto social, iniciando-se o processo ressocializador ${ }^{14}$.

A LEP (Lei de Execução Penal) elenca algumas condições para o apenado habilitar-se a realizar o trabalho interno no cárcere e também estudar. Primeiramente, tais indivíduos devem estar cumprindo pena no regime fechado ou no semiaberto, na sequência, dá-se ênfase a sua condição pessoal, bem como as oportunidades disponibilizadas no mercado de trabalho e as suas necessidades futuras.

O direito ao estudo e ao trabalho no cárcere são requisitos essenciais no processo de ressocialização, visto que o dever do estudo ou trabalho se coaduna com o dever do Estado de oportunizar a esses indivíduos o exercício de uma atividade produtiva, reinserindo-os na sociedade de forma digna ${ }^{15}$.

Em função do trabalho ou estudo realizado pelo apenado, necessário se faz conceituar o instituto da remição que se encontra disciplinado no artigo 126 da LEP, com nova redação dada

\footnotetext{
${ }^{10}$ NETO, Eurico Bitencourt. O direito ao mínimo para uma vida digna. Porto Alegre: Livraria do Advogado Editora, 2010.

${ }^{11}$ FOUCAULT, Michel. Vigiar e punir. 41. ed. Petrópolis: Vozes, 2014.

${ }^{12}$ FOUCAULT, Michel. Vigiar e punir. 41. ed. Petrópolis: Vozes, 2014.

${ }^{13}$ CARNELUTTI, Francesco. As Misérias do Processo Penal. 1. ed. Campinas: Russell, 2008.

${ }^{14}$ AVENA, Norberto Cláudio Pâncaro. Execução penal: esquematizado. 4. ed. Rio de Janeiro: Forense; São Paulo: Método, 2017.

${ }^{15}$ AVENA, Norberto Cláudio Pâncaro. Execução penal: esquematizado. 4. ed. Rio de Janeiro: Forense; São Paulo: Método, 2017.
} 
pela Lei 12.433/2011, que acrescentou as atividades de estudo como forma de remição junto ao trabalho.

Art. 126. O condenado que cumpre a pena em regime fechado ou semiaberto poderá remir, por trabalho ou por estudo, parte do tempo de execução da pena. (Redação dada pela Lei $\mathrm{n}^{\circ} 12.433$, de 2011).

$\S 1^{\circ}$ A contagem de tempo referida no caput será feita à razão de: (Redação dada pela Lei $\mathrm{n}^{\circ} 12.433$, de 2011)

I - 1 (um) dia de pena a cada 12 (doze) horas de frequência escolar - atividade de ensino fundamental, médio, inclusive profissionalizante, ou superior, ou ainda de requalificação profissional - divididas, no mínimo, em 3 (três) dias; (Incluído pela Lei $\mathrm{n}^{\circ} 12.433$, de 2011)

II - 1 (um) dia de pena a cada 3 (três) dias de trabalho. (Incluído pela Lei no 12.433, $\underline{\text { de 2011) }}$

$\S 2^{\underline{o}}$ As atividades de estudo a que se refere o $\S 1^{\mathrm{o}}$ deste artigo poderão ser desenvolvidas de forma presencial ou por metodologia de ensino a distância e deverão ser certificadas pelas autoridades educacionais competentes dos cursos frequentados. (Redação dada pela Lei $n^{\circ} 12.433$, de 2011)

A remição é um direito do réu que cumpre pena no regime fechado ou no semiaberto de ter sua pena privativa de liberdade reduzida, em razão do exercício de atividade laboral ou estudo. Portanto, os indivíduos que estão cumprindo pena no regime aberto ou no livramento condicional não gozam de tal direito ${ }^{16}$.

O objetivo principal do instituto da remição, ou melhor, do benefício desse direito, é auxiliar no processo de ressocialização do encarcerado, através do incentivo do bom comportamento do apenado no exercício da atividade laboral e de estudo.

A Lei 12.433/2011 proporcionou à Lei de Execução Penal um grande avanço no sentido de reconhecer o direito à educação, junto ao direito do trabalho, como um passo à cidadania e dignificação do apenado.

A recepção do conceito de cidadania pelo ordenamento constitucional é uma inovação da atual da Carta Constitucional, uma vez, que ele está inserido no rol dos direitos sociais, previsto no art. $6^{\circ}$ do referido diploma legal, onde o sujeito de direito encontra-se individualizado. Flávia Piovesan esclarece que

Como já visto, a Carta de 1988 é a primeira Constituição que integra ao elenco dos direitos fundamentais os direitos sociais que nas Cartas anteriores restavam pulverizados no capítulo pertinente à ordem econômica e social. A opção da Carta é clara ao afirmar que os direitos sociais são direitos fundamentais, sendo pois inconcebível separar os valores liberdade (direitos civis e políticos) e igualdade (direitos sociais, econômicos e culturais). Logo, a Constituição de 1988 acolhe a concepção contemporânea de cidadania no que diz respeito à indivisibilidade dos direitos humanos ${ }^{17}$.

Antes mesmo de qualquer previsão legal, o direito à educação, conforme já mencionado, está assegurado, de forma expressa, na Constituição Federal, como, por exemplo, no artigo $6^{\circ}$, e nos artigos 205 e seguintes. Há, ainda, a Lei 9.394/1996, que versa sobre "as diretrizes e bases da educação nacional".

O artigo 205, da Constituição Federal de 1988, versa no seguinte norte:

Art. 205. A educação, direito de todos e dever do Estado e da família, será promovida e incentivada com a colaboração da sociedade, visando ao pleno desenvolvimento da pessoa, seu preparo para o exercício da cidadania e sua qualificação para o trabalho.

\footnotetext{
${ }^{16}$ AVENA, Norberto Cláudio Pâncaro. Execução penal: esquematizado. 4. ed. Rio de Janeiro: Forense; São Paulo: Método, 2017.

${ }^{17}$ PIOVESAN, Flávia. Temas de direitos humanos. 3 ed. São Paulo: Saraiva, 2009, p. 328-329.
}

Revista de Direito Brasileira | São Paulo, SP | v. 21 | n. 8 | p.6-21 |Set./Dez. 2018 
Com redação semelhante, é o artigo $2^{\circ}$, da Lei 9.394/1996:

Art. $2^{\circ}$ A educação, dever da família e do Estado, inspirada nos princípios de liberdade e nos ideais de solidariedade humana, tem por finalidade o pleno desenvolvimento do educando, seu preparo para o exercício da cidadania e sua qualificação para o trabalho.

Da análise dos diplomas acima transcritos, é possível afirmar que a educação consiste em um direito de todos, bem como, um dever do Estado em colaborar na promoção e incentivo da educação, ainda mais quando se trata da Lei de Execução Penal.

A educação, nos termos do diploma constitucional, visa ao pleno desenvolvimento da pessoa, seu preparo para o exercício da cidadania e sua qualificação para o trabalho, sendo tal entendimento descrito, também, no diploma legal, que aponta, ainda que a educação seja inspirada nos princípios da liberdade e nos ideais de solidariedade humana ${ }^{18}$.

Igualmente importante, é o teor do artigo $1^{\circ}$, da Lei 9.394/1996, que dispõe que:

Art. $1^{\circ}$ A educação abrange os processos formativos que se desenvolvem na vida familiar, na convivência humana, no trabalho, nas instituições de ensino e pesquisa, nos movimentos sociais e organizações da sociedade civil e nas manifestações culturais.

Trata-se, por conseguinte, de um direito complexo, uma vez que se atrela à formação do indivíduo, ao seu pleno desenvolvimento, bem como atrelado a outros direitos, como, por exemplo, o exercício da cidadania e a qualificação para o trabalho, sendo fundamental, não apenas para à pessoa em si considerada, mas também para a convivência na sociedade e acrescentando, para ressocialização ${ }^{19}$.

A educação é um direito complexo, uma vez que é objeto de várias pretensões de direito, seja dos pais, dos governos, das religiões ou dos educandos, sendo, portanto, de interesse não apenas do sujeito individualmente considerado, mas também como direito coletivo, isto é, próprio da sociedade ${ }^{20}$.

É possível, assim, falar em uma concepção humanista da educação, já que orientada pelo pleno desenvolvimento da pessoa, conforme artigos $2^{\circ}$ e 22 da Lei 9.394/96, bem como, pelo artigo 205, da Constituição Federal de 1988, o que aponta, por exemplo, um horizonte promissor para a superação da cultura da exclusão ${ }^{21}$.

Segundo o artigo 22, da Lei 9.394/96, em compasso com outros dispositivos já transcritos, em especial, o artigo $2^{\circ}$ da mesma lei e o artigo 205, da Constituição Federal:

Art. 22. A educação básica tem por finalidades desenvolver o educando, assegurar-lhe a formação comum indispensável para o exercício da cidadania e fornecer-lhe meios para progredir no trabalho e em estudos posteriores.

\footnotetext{
${ }^{18}$ RIZZI, Ester; GONZALEZ, Marina; XIMENES, Salomão. Direito Humano à Educação. 2. ed. rev. e atual., 2011. Disponível em: http://www.direitoaeducacao.org.br/wp-content/uploads/2011/12/manual_dhaaeducacao_2011.pdf . Acesso em: 08 de dezembro de 2016.

${ }^{19}$ BARUFFI, Helder. Educação como Direito Fundamental: um princípio a ser realizado. In: FACHIN, Zulmar (Coord.). Direitos Fundamentais e Cidadania. São Paulo: Método, 2008.

${ }^{20}$ BARUFFI, Helder. Educação como Direito Fundamental: um princípio a ser realizado. In: FACHIN, Zulmar (Coord.). Direitos Fundamentais e Cidadania. São Paulo: Método, 2008.

${ }^{21}$ ARROYO, Miguel G. Fracasso/Sucesso: um pesadelo que perturba nossos sonhos. Em Aberto, Brasília, vol. 17, $\mathrm{n}$. 71, p. 33-40, jan. 2000. Disponível em: http://emaberto.inep.gov.br/index.php/emaberto/article/viewFile/2100/2069 . Acesso em: 08 de dezembro de 2016.
} 
Desta feita, a educação possibilita o pleno desenvolvimento da personalidade humana, já que por seu intermédio a pessoa conquista sua liberdade e sua ascensão social, o que possibilita, igualmente, sua integração na sociedade, logo, permite a efetivação da cidadania ${ }^{22}$.

A educação é fundamental para despertar a consciência dos indivíduos, para superação das contradições, dada à temática do presente estudo. A prática educacional não deve servir apenas para modelar os apenados, nem mesmo se reduzir a mera transmissão de conhecimentos, mas sim oportunizar a produção de uma consciência verdadeira, de pessoas capazes de reconhecer a sociedade altamente ideologizada em que vivem.

Enfatiza-se que o direito à educação é um direito subjetivo, essencial, necessário à própria existência do ser humano como um ser social, e que está intimamente ligado ao livre desenvolvimento da personalidade e à dignidade da pessoa humana, pode ser considerado além de um direito fundamental social também um direito da personalidade.

Sobre a temática, Clarice Seixas Duarte afirma que:

O direito à educação não se reduz ao direito do indivíduo de cursar o ensino fundamental para alcançar melhores oportunidades de emprego e contribuir para o desenvolvimento econômico da nação. Deve ter como escopo o oferecimento de condições para o desenvolvimento pleno de inúmeras capacidades individuais, jamais se limitando às exigências do mercado de trabalho, pois o ser humano é fonte inesgotável de crescimento e expansão no plano intelectual, físico, espiritual, moral, criativo e social ${ }^{23}$.

Trata-se de um direito fundamental, igualmente, um direito humano, previsto, inclusive, de forma expressa, na Declaração Universal dos Direitos Humanos, de 1948, em seu artigo XXVI, bem como em outros diplomas internacionais, como, por exemplo, Pacto Internacional dos Direitos Econômicos, Políticos e Sociais.

Assim, é possível apontar sobre o direito à educação que:

Além de sua importância como direito humano que possibilita à pessoa desenvolver-se plenamente e continuar aprendendo ao longo da vida, a educação é um bem público da sociedade, na medida em que possibilita o acesso aos demais direitos. Portanto, a educação é um direito muito especial: um "direito habilitante" ou "direito de síntese". E sabe por quê? Porque uma pessoa que passa por um processo educativo adequado e de qualidade pode exigir e exercer melhor todos os seus direitos ${ }^{24}$.

O direito à educação, por conseguinte, é um direito complexo, uma vez que se atrela à formação do indivíduo, ao seu pleno desenvolvimento, bem como atrelado a outros direitos, como, por exemplo, o exercício da cidadania e a qualificação para o trabalho, sendo fundamental, não apenas para à pessoa em si considerada, mas também para a convivência na sociedade e, acrescentando, a reeducação e ressocialização dos apenados.

A educação, como um direito complexo, é objeto de várias pretensões de direito, seja dos governos, das religiões ou dos próprios apenados, sendo, portanto, de interesse não apenas do

\footnotetext{
22 MOTTA, Ivan Dias da; LOPES, Mariane Helena. O sistema de cotas sociais para ingresso na universidade pública. Encontro Nacional do CONPEDI, 20, 2011. Belo Horizonte, MG. Anais eletrônicos do XX Congresso Brasileiro do CONPEDI. Florianópolis: Fundação Boiteux, 2011, p. 4341. Disponível em: http://www.publicadireito.com.br/artigos/?cod=9aa70957fde5ac24 . Acesso em: 08 de dezembro de 2016.

${ }^{23}$ DUARTE, Clarice Seixas. Direito público subjetivo e políticas educacionais. In: BUCCI, Maria Paula Dallari. Políticas públicas: reflexões sobre o conceito jurídico. São Paulo: Saraiva, 2006, p. 271.

${ }^{24}$ RIZZI, Ester; GONZALEZ, Marina; XIMENES, Salomão. Direito Humano à Educação. 2. ed. rev. e atual., 2011, p. 19. Disponível em: http://www.direitoaeducacao.org.br/wpcontent/uploads/2011/12/manual_dhaaeducacao_2011.pdf . Acesso em: 08 de dezembro de 2016.
} 
sujeito individualmente considerado, mas também como direito coletivo, isto é, próprio da sociedade ${ }^{25}$.

Em verdade, o direito à educação consiste em um dever do Estado, devendo ser prestado com qualidade devido sua importância para o indivíduo em si considerado, bem como, perante a sociedade, sendo que, a principal atuação do Estado ocorre por intermédio das políticas públicas, objeto de estudo do próximo capítulo.

Mônica Caggiano aponta no mesmo sentido, afirmando que:

Vislumbra-se o direito à educação como conteúdo multifacetado, envolvendo não apenas o direito à instrução como um processo de desenvolvimento individual, mas, também, o direito a uma política educacional, ou seja, a um conjunto de intervenções juridicamente organizadas e executadas em termos de um processo de formação da sociedade, visando oferecer aos integrantes da comunidade social instrumentos a alcançar os seus fins ${ }^{26}$.

Nesta circunstância, afirmam Rogério Luiz Nery da Silva e Daiane Garcia Masson:

A educação exerce papel essencial na vida das pessoas sendo fundamento basilar na gênese da consciência e dos valores morais e mesmo assecuratório da dignidade. [...] Além da importância do papel da família e da sociedade, em conjunto pela educação informal como elemento de integração do indivíduo no seu seio, também o Estado tem o dever jurídico de garantir francas oportunidades de educação formal a todos, com a finalidade de propiciar preparação para a inserção no mercado de trabalho, com consequente ampliação do grau de desenvolvimento e da qualidade de vida, como elemento central de construção e reconstrução da personalidade humana. Em razão de a educação visar à melhoria da qualidade de vida das pessoas e de reduzir as desigualdades sociais, justificase o acesso e permanência na escola, com ensino de qualidade, tornando inadiável a solução dos problemas relativos à efetivação desse direito ${ }^{27}$.

Desta feita, é admissível afirmar que a educação é um direito da personalidade, pois indispensável para a dignificação humana.

Eduardo Bittar enaltece que o direito à educação carrega em si as características dos direitos da personalidade, ou seja, trata-se de um direito natural, imanente, absoluto, oponível erga omnes, inalienável, impenhorável, imprescritível, irrenunciável [...] não se sujeitando aos caprichos do Estado ou à vontade do legislador, pois se trata de algo ínsito à personalidade humana desenvolver, conforme a própria estrutura e constituição humana ${ }^{28}$.

O direito educacional é um direito da personalidade, pois imprescindível para o desenvolvimento da personalidade humana e está intimamente ligado ao princípio da dignidade da pessoa humana. Esse é o posicionamento de Pedro Ferreira de Freitas e Ivan Dias da Motta:

O fato é, que, reconhecidos como direitos inatos ou não, os direitos da personalidade se constituem em direitos mínimos que visam assegurar e resguardar a dignidade da pessoa humana e como tais devem estar previstos e sancionados pelo ordenamento jurídico, não de forma estanque e limitada, mas levando-se em consideração o reconhecimento de um

\footnotetext{
${ }^{25}$ BARUFFI, Helder. Educação como Direito Fundamental: um princípio a ser realizado. In: FACHIN, Zulmar (Coord.). Direitos Fundamentais e Cidadania. São Paulo: Método, 2008.

${ }^{26}$ CAGGIANO, Mônica H.S. A educação: direito fundamental. In: RANIERI, Nina B. S. (Coord.); RIGHETTI, Sabine (Org.). Direito à educação: aspectos constitucionais. São Paulo: EDUSP, 2009, p. 23.

${ }^{27}$ SILVA, Rogério Luiz Nery da; MASSON, Daiane Garcia. O Plano de Desenvolvimento da Educação como Política Pública de Efetivação do Direito Fundamental Social à Educação. XXIV Encontro Nacional do CONPEDI-UFS. Direito, Educação e Metodologias do Conhecimento. Florianópolis, 2015. Disponível em: http://www.conpedi.org.br/publicacoes/c178h0tg/017e0bex . Acesso em: 08 de dezembro de 2016.

${ }^{28}$ BITTAR, Eduardo C.B. Direito e ensino jurídico: legislação educacional. São Paulo: Atlas, 2001, p. 158. Revista de Direito Brasileira | São Paulo, SP | v. 21 | n. 8 | p. 6-21 |Set./Dez. 2018
} 
direito geral de personalidade, a que se remeteriam todos os outros tipos previstos ou não no sistema jurídico ${ }^{29}$.

Quando se priva o indivíduo do acesso à educação, na verdade se viola o princípio da dignidade da pessoa humana, vez que "a falta do ato educacional, alija o indivíduo de ter acesso a outros direitos e condições básicas da vida, como emprego, bens e serviços" ${ }^{30}$, até porque a educação assume a função da construção da cidadania de forma que assumir a educação como prioridade é "respeitar o princípio da dignidade da pessoa humana, haja vista das condições aos que ela têm acesso, de exercer os demais direitos fundamentais e desfrutar melhores condições de vida" 31 .

A propósito, uma educação de qualidade não se faz somente com insumos, mas também com professores bem formados e valorizados, gerando assim práticas pedagógicas capazes de desmascarar todas as contradições e a opressão dessa atual sociedade capitalista. Se esse apenado que esta cumprindo pena no regime fechado recebe uma educação ideologizada e desprovida de senso crítico, como irá se posicionar num mundo cheio de conflitos, do qual ele já foi uma das vítimas?

Para Miguel Gonzalez Arroyo:

O desafio é constante, e a finalidade maior da educação não se limita apenas ao processo de humanização, mas na recuperação da humanidade dos oprimidos/excluídos. E, enquanto o princípio da educação estiver voltado para o mercado, a educação será pobre e deficitária em sua formação, pois não visa o desenvolvimento do indivíduo, apenas o seu adestramento, a sua qualificação manual, em detrimento do ensino centrado na criticidade e na formação do pensamento ${ }^{32}$.

O modelo contra ideológico de educação implica em práticas pedagógicas que levem o sujeito a pensar por si só, analisar ver o que está errado e agir, tomar partido, se envolver, ter atitude e ir em busca de solução. O indivíduo órfão de cidadania vive à deriva, sem direção, torna-se vítima das circunstâncias.

Para encerrar, mas sem finalizar a discussão do direito à educação, é preciso compreender que o indivíduo sentenciado e que esteja cumprindo pena em estabelecimento fechado necessita de oportunidades sociais e educacionais que não estejam alienadas e ancoradas na passividade, as quais silenciam a liberdade de expressão desse indivíduo, renegando sua trajetória pessoal e social.

\section{A INCLUSÃO DA EDUCAÇÃO A DISTÂNCIA NO SISTEMA PENITENCIÁRIO}

\footnotetext{
${ }^{29}$ FREITAS, Pedro Ferreira de; MOTTA, Ivan Dias da. O direito à educação como direito da personalidade e mínimo existencial. Revista Jurídica do CESUCA, Cachoeirinha-RS, v.3, n. 6, dez/2015. Disponível em: http://www.egov.ufsc.br:8080/portal/conteudo/o-direito-\%C3\%A0-educa\%C3\%A7\%C3\%A3o-como-direito-dapersonalidade-e-m\%C3\%ADnimo-existencial . Acesso em: 08 de dezembro de 2016.

${ }^{30}$ FREITAS, Pedro Ferreira de; MOTTA, Ivan Dias da. O direito à educação como direito da personalidade e mínimo existencial. Revista Jurídica do CESUCA, Cachoeirinha-RS, v.3, n. 6, dez/2015. Disponível em: http://www.egov.ufsc.br:8080/portal/conteudo/o-direito-\%C3\%A0-educa\%C3\%A7\%C3\%A3o-como-direito-dapersonalidade-e-m\%C3\%ADnimo-existencial . Acesso em: 08 de dezembro de 2016, p. 47.

${ }^{31}$ SILVA, Rogério Luiz Nery da; MASSON, Daiane Garcia. O Plano de Desenvolvimento da Educação como Política Pública de Efetivação do Direito Fundamental Social à Educação. XXIV Encontro Nacional do CONPEDI-UFS. Direito, Educação e Metodologias do Conhecimento. Florianópolis, 2015, p. 434. Disponível em: http://www.conpedi.org.br/publicacoes/c178h0tg/017e0bex . Acesso em: 08 de dezembro de 2016.

32 ARROYO, Miguel G. Fracasso/Sucesso: um pesadelo que perturba nossos sonhos. Em Aberto, Brasília, vol. 17, n. 71, p. 33-40, jan. 2000, p. 787-807. Disponível em: http://emaberto.inep.gov.br/index.php/emaberto/article/viewFile/2100/2069 . Acesso em: 08 de dezembro de 2016.
} 
A educação a distância possibilita a democratização do acesso à educação em locais distantes dos grandes centros urbanos. Entretanto, pode-se estender este valor estratégico aos presídios, favorecendo o direito à educação àqueles que estão privados de sua liberdade.

Além desse aspecto, destaca-se o incentivo à autonomia nos estudos e a possibilidade de remição de parte do tempo de execução da pena de acordo com a Lei de Execução Penal.

O ensino à distância com previsão legal a partir da publicação da Lei Federal no 9.394/1996 que disciplina as Diretrizes e Bases da Educação Nacional:

Art. 80. O Poder Público incentivará o desenvolvimento e a veiculação de programas de ensino a distância, em todos os níveis e modalidades de ensino, e de educação continuada.

Sua regulamentação sucedeu com o Decreto Federal $n^{\circ} 5.622 / 2005$ que foi a revogado recentemente pelo Decreto $n^{\circ} 9.057$ de 2017 e trouxe a definição do ensino a distância:

Art. $1^{\circ}$. Para os fins deste Decreto, considera-se educação a distância a modalidade educacional na qual a mediação didático-pedagógica nos processos de ensino e aprendizagem ocorra com a utilização de meios e tecnologias de informação e comunicação, com pessoal qualificado, com políticas de acesso, com acompanhamento e avaliação compatíveis, entre outros, e desenvolva atividades educativas por estudantes e profissionais da educação que estejam em lugares e tempos diversos.

O referido Decreto $n^{\circ}$ 9.057/2017 regulamentou o artigo 80 da Lei n $^{\circ}$ 9.394/1996 e dispôs em seu artigo $9^{\circ}$, inciso $\mathrm{V}$, o seguinte:

Art. $9^{\circ}$ A oferta de ensino fundamental na modalidade a distância em situações emergenciais, previstas no $\S 4^{\circ}$ do art. 32 da Lei $\mathrm{n}^{\circ}$ 9.394, de 1996, se refere a pessoas que:

V - estejam em situação de privação de liberdade.

A educação trata-se de um direito de todos, inclusive dos apenados, e um dever do Estado, sendo que, ao Estado compete assegurar não apenas o mínimo existencial a todos, mas atuar na prestação da educação com qualidade em qualquer lugar que seja.

E hoje a realidade é que o estudo à distância se encontra em uma crescente no Brasil, conquistando cada vez mais pessoas, tanto do interior quanto dos grandes centros urbanos, interessadas e motivadas em ver realmente atendido seu direito constitucional de acesso à educação de qualidade. E porque não estender esse nobre direito aos apenados, que dentre outros fatores, estão em tal condição pela falta de oportunidades, inclusive pelo não acesso à educação básica?

\section{POLÍticas públicas EDUCACIONAIS COM ATUAÇÃo NO SISTEMA PENITENCIÁRIO BRASILEIRO}

Como amplamente discutido, a educação consiste em um direito de todos e um dever do Estado e da família, em colaboração com a sociedade, nos termos do artigo 205, da Constituição Federal. Esta obrigação imposta ao Estado tem como principal instrumento de efetivação as políticas públicas, em especial a educacional.

A partir desse ponto que se dá ênfase à atuação estatal, que ocorre, em essência, por intermédio das políticas públicas, no caso, políticas públicas de promoção humana, uma vez que a educação está ligada ao pleno desenvolvimento da pessoa, à formação de sua personalidade.

Inicialmente, cumpre apontar a definição do termo política pública, nas palavras de Ivan Dias da Motta e Tatiana Richetti são: 
o meio pelo qual se possibilita a verdadeira concretização das normas constitucionais de maior relevância como os direitos fundamentais, em especial, os de natureza social, a exemplo do direito à educação, cuja viabilidade é elemento determinante para o exercício das liberdades individuais e da própria democracia, traduzindo-se na mais notável via de efetivação. O sistema educacional deve proporcionar oportunidades de desenvolvimento nestas diferentes dimensões, preocupando-se em fomentar valores como o respeito aos direitos humanos e a tolerância, além da participação social na vida pública, sempre em condição de liberdade e dignidade. Assim, no Estado Social, a proteção do direito individual faz parte do bem comum $^{33}$.

Política pública, também conceituada como "um programa ou quadro de ação governamental, porque consiste num conjunto de medidas articuladas (coordenadas), cujo escopo é dar impulso, isto é, movimentar a máquina do governo, no sentido de realizar algum objetivo de ordem pública, ou, na ótica dos juristas, concretizar um direito" 34 .

No mesmo sentido, é o posicionamento de Fernando Aith, para quem:

A promoção e proteção dos direitos humanos e demais direitos reconhecidos em um ordenamento jurídico são realizadas, pelo Estado, através de políticas públicas (política de segurança, política de saúde, política de educação, política de democratização dos meios de comunicação etc.). A elaboração dessas políticas deve estar em consonância com os ditames da Constituição e dos demais instrumentos normativos do ordenamento jurídico, bem como deve sempre ter como finalidade o interesse público e a promoção e proteção de direitos, em especial aqueles reconhecidos como direitos humanos ${ }^{35}$.

As políticas públicas afetas à educação, por conseguinte, inserem-se nesse contexto, uma vez que apontam como objetivo à promoção e a proteção do direito à educação, um direito fundamental, constitucionalmente assegurado.

A educação como visto anteriormente íntegra o mínimo existencial e as necessidades básicas ao desenvolvimento pleno da pessoa, a uma vida digna. Nesse sentido, exsurge a importância das políticas públicas, conforme afirma Potyara Amazoneida Pereira Pereira: "No marco da recente valorização do estatuto da cidadania, o conceito de necessidades básicas assumiu papel preponderante na justificação dos direitos sociais e das políticas públicas que lhe são correspondentes" 36 . Em verdade,

As políticas públicas são o meio pelo qual se possibilita a verdadeira concretização das normas constitucionais de maior relevância como os direitos fundamentais, em especial os de natureza social, a exemplo do direito à educação, cuja viabilidade é elemento determinante para o exercício das liberdades individuais e da própria democracia, traduzindo-se na mais notável via de efetivação. O sistema educacional deve proporcionar oportunidades de desenvolvimento nestas diferentes dimensões, preocupando-se em fomentar valores como o respeito aos direitos humanos e a tolerância, além da participação social na vida pública, sempre em condição de liberdade e dignidade. Assim, no Estado Social, a proteção do direito individual faz parte do bem comum ${ }^{37}$.

\footnotetext{
${ }^{33}$ MOTTA, Ivan Dias da; RICHETTI, Tatiana. Da necessidade de efetivação do direito à educação por meio de políticas públicas. XXII Encontro Nacional do CONPEDI. Anais eletrônicos do XXII Congresso Nacional do CONPEDI. Curitiba, 2013, p. 246-268. Disponível em: http://www.publicadireito.com.br/artigos/?cod=9aa70957fde5ac24. Acesso em: 08 de dezembro de 2016.

${ }_{34}$ BUCCI, Maria Paula Dallari Bucci. O conceito de política pública em direito. In: BUCCI, Maria Paula Dallari. Políticas públicas: reflexões sobre o conceito jurídico. São Paulo: Saraiva, 2006, p. 14.

${ }^{35}$ AITH, Fernando. Políticas Públicas de Estado e de Governo: instrumentos de consolidação do Estado Democrático de Direito e de promoção e proteção dos direitos humanos. In: BUCCI, Maria Paula Dallari. Políticas públicas: reflexões sobre o conceito jurídico. São Paulo: Saraiva, 2006, p. 218-219.

${ }^{36}$ PEREIRA, Potyara A.P. Necessidades Humanas: subsídios à crítica dos mínimos sociais. São Paulo: Cortez, 2011. ${ }^{37}$ MOTTA, Ivan Dias da; RICHETTI, Tatiana. Da necessidade de efetivação do direito à educação por meio de políticas públicas. XXII Encontro Nacional do CONPEDI. Anais eletrônicos do XXII Congresso Nacional do Revista de Direito Brasileira | São Paulo, SP | v. 21 | n. 8 | p.6-21 |Set./Dez. 2018
} 
Assim, a atuação do Estado é de fundamental importância para a concretização do direito à educação, na modalidade à distância, no sistema penitenciário, considerado um direito fundamental, de grande relevância na atualidade, seja para a formação da personalidade, seja para sua participação na sociedade, como, por exemplo, para o exercício da cidadania e ressocialização do apenado. Isso porque,

O sistema educacional deve proporcionar oportunidades de desenvolvimento nestas diferentes dimensões, preocupando-se em fomentar valores como o respeito aos direitos humanos e a tolerância, além da participação social na vida pública, sempre em condição de liberdade e dignidade. Assim, no Estado Social, a proteção do direito individual faz parte do bem comum ${ }^{38}$.

Outro marco importante em relação às políticas públicas educacionais é o Plano Nacional de Educação, previsto de forma expressa na Constituição Federal:

Art. 214. A lei estabelecerá o plano nacional de educação, de duração decenal, com o objetivo de articular o sistema nacional de educação em regime de colaboração e definir diretrizes, objetivos, metas e estratégias de implementação para assegurar a manutenção e desenvolvimento do ensino em seus diversos níveis, etapas e modalidades por meio de ações integradas dos poderes públicos das diferentes esferas federativas que conduzam a: I - erradicação do analfabetismo;

II - universalização do atendimento escolar;

III - melhoria da qualidade do ensino;

IV - formação para o trabalho;

V - promoção humanística, científica e tecnológica do País.

VI - estabelecimento de meta de aplicação de recursos públicos em educação como proporção do produto interno bruto.

Da leitura do artigo acima transcrito, é possível concluir que o Plano Nacional de Educação estabelece as diretrizes, objetivos e as estratégias de implementação, manutenção e desenvolvimento do ensino, sendo que as ações, que devem ser integradas por parte dos poderes públicos, devem conduzir a vários pontos, como, por exemplo, a erradicação do analfabetismo, formação para o trabalho, promoção humanística, o que ressalta a importância do direito à educação e, por conseguinte, das respectivas políticas públicas ${ }^{39}$. Acrescentando a oportunidade de remição da pena, bem como a ressocialização do apenado com disposição na Lei de Execução Penal, e ainda o fácil acesso a essas garantias através da educação à distância.

Assim, uma vez que se trata de direito necessário ao pleno desenvolvimento da pessoa, à sua dignificação, integrando o chamado mínimo existencial (ou uma necessidade básica), não pode ficar sujeito a normas programáticas, devendo o Estado efetivar referido direito por intermédio de políticas públicas, devendo, ainda, o Judiciário atuar, quando necessário, para a garantia da Constituição e dos objetivos que norteiam o Estado Democrático de Direito ${ }^{40}$.

CONPEDI. Curitiba, 2013, p. 246-268. Disponível em: http://www.publicadireito.com.br/artigos/?cod=9aa70957fde5ac24. Acesso em: 08 de dezembro de 2016. ${ }^{38}$ MOTTA, Ivan Dias da; RICHETTI, Tatiana. Da necessidade de efetivação do direito à educação por meio de políticas públicas. XXII Encontro Nacional do CONPEDI. Anais eletrônicos do XXII Congresso Nacional do CONPEDI. Curitiba, 2013, p. 246-268. Disponível em: http://www.publicadireito.com.br/artigos/?cod=9aa70957fde5ac24. Acesso em: 08 de dezembro de 2016.

${ }^{39}$ DUARTE, Clarice Seixas. Direito público subjetivo e políticas educacionais. In: BUCCI, Maria Paula Dallari. Políticas públicas: reflexões sobre o conceito jurídico. São Paulo: Saraiva, 2006.

${ }^{40}$ MOTTA, Ivan Dias da; RICHETTI, Tatiana. Da necessidade de efetivação do direito à educação por meio de políticas públicas. XXII Encontro Nacional do CONPEDI. Anais eletrônicos do XXII Congresso Nacional do Revista de Direito Brasileira | São Paulo, SP | v. 21 | n. 8 | p. 6-21 |Set./Dez. 2018 
O direito à educação no sistema penitenciário, diante da presente pesquisa, consiste em um direito necessário à promoção humana, ou seja, um direito de todos. Já o Estado figura nesse cenário como um dos obrigados, senão o principal, na prestação de tal direito, impondo-se uma atividade prestacional por parte do mesmo, cuja principal forma de atuação se dá por intermédio das políticas públicas educacionais, com a inovação da educação na modalidade à distância.

\section{CONCLUSÃO}

É repugnante confessar que o sistema prisional propicia um ambiente em que nada auxilia para a ressocialização dos apenados, e sim a formação de um aprendizado das técnicas para a continuidade na prática de crimes.

Neste contexto que se fundamentou a presente pesquisa, como reconhecer e efetivar os direitos fundamentais e a dignidade humana daquele que se encontra encarcerado?

Como exaustivamente abordado, a educação é o elemento necessário ao pleno desenvolvimento da pessoa humana, ou seja, à formação de sua personalidade, à sua dignificação, de onde se extrai a fundamentalidade de tal direito.

A educação a distância vem possibilitar que o direito a educação seja multiplicado irrestritamente, alcançando populações excluídas e, muitas vezes, condenadas a regressar à realidade de crime e violência por falta de oportunidades.

Em razão de suas características e de seu papel para a formação do indivíduo, bem como, para o exercício de outros direitos e consequente atuação perante à sociedade, como, por exemplo, o exercício da cidadania, a qualificação para o trabalho e a ressocialização, é crível apontar o direito à educação como integrante do mínimo existencial.

Uma vez que se trata de um elemento caracterizador do mínimo existencial, o seu exercício não pode ser postergado, devendo, por conseguinte, ser prioridade do Estado, ou seja, é preciso uma atuação efetiva estatal.

A principal forma de atuação do Estado, sendo que se trata de um dever do mesmo assegurar o direito à educação, e, que tal prestação seja realizada com qualidade, é por intermédio das políticas públicas, que, nesse caso, configuram políticas educacionais de promoção humana, em especial na modalidade à distância.

A ressocialização do indivíduo objetiva promover e incentivar a reintegração do apenado ao convívio social, tendo como fatores fundamentais a responsabilidade e o compromisso tanto da sociedade quanto do Estado.

Deve-se, portanto, utilizar amplamente o direito à educação a distância aos apenados como principal alternativa de ressocialização, pois o respeito à dignidade dos mesmos somente será alcançado no instante em que a aplicação das penas tornarem-se mais humanas, através da amenização das diferenças entre a vida no interior e fora do cárcere.

\section{REFERÊNCIAS}

AITH, Fernando. Políticas Públicas de Estado e de Governo: instrumentos de consolidação do Estado Democrático de Direito e de promoção e proteção dos direitos humanos. In: BUCCI, Maria Paula Dallari. Políticas públicas: reflexões sobre o conceito jurídico. São Paulo: Saraiva, 2006.

CONPEDI. Curitiba, 2013, p. $\quad$ 246-268. $\quad$ Disponível em: http://www.publicadireito.com.br/artigos/?cod=9aa70957fde5ac24. Acesso em: 08 de dezembro de 2016. 
ARROYO, Miguel G. Fracasso/Sucesso: um pesadelo que perturba nossos sonhos. Em Aberto, Brasília, vol. 17, n. 71, p. 33-40, jan. 2000. Disponível em:

http://emaberto.inep.gov.br/index.php/emaberto/article/viewFile/2100/2069 . Acesso em: 08 de dezembro de 2016.

AVENA, Norberto Cláudio Pâncaro. Execução penal: esquematizado. 4. ed. Rio de Janeiro: Forense; São Paulo: Método, 2017.

BARUFFI, Helder. Educação como Direito Fundamental: um princípio a ser realizado. In: FACHIN, Zulmar (Coord.). Direitos Fundamentais e Cidadania. São Paulo: Método, 2008.

BARROSO, Luís Roberto. A dignidade da pessoa humana no direito constitucional contemporâneo: a construção de um conceito jurídico à luz da jurisprudência mundial. Tradução Humberto Laport de Mello. $3^{\mathrm{a}}$ reimpressão. Belo Horizonte: Fórum, 2014.

BECCARIA, Cesare. Dos Delitos e Das Penas. São Paulo: Martin Claret, 2003.

BITENCOURT, Cezar Roberto. Tratado de Direito Penal - Parte Geral. 9. ed. São Paulo: Saraiva, 2004.

BITTAR, Eduardo C.B. Direito e ensino jurídico: legislação educacional. São Paulo: Atlas, 2001.

BONAVIDES, Paulo. Curso de Direito Constitucional. 31. ed. São Paulo: Malheiros, 2016.

BRASIL. Constituição Federal (1988). Constituição da República Federativa do Brasil. Brasília, DF: Senado, 1988. Disponível em:

http://www.planalto.gov.br/ccivil_03/constituicao/constituicaocompilado.htm. Acesso em: 30 de outubro de 2017.

BRASIL. Lei no 7.210, de 11 de julho de 1984. Lei de Execução Penal. Brasília, DF: Senado, 1984. Disponível em: http://www.planalto.gov.br/ccivil_03/leis/L7210compilado.htm. Acesso em: 30 de outubro de 2017.

BRASIL. Lei no 9.394, de 20 de dezembro de 1996. Brasilia, DF: Senado, 1996. Disponível em: http://www.planalto.gov.br/ccivil 03/leis/L9394.htm. Acesso em: 30 de outubro de 2017.

BRASIL. Decreto n 9.057, de 25 de maio de 2017. Brasilia, DF: Senado, 1996. Disponível em: http://www.planalto.gov.br/ccivil_03/_Ato2015-2018/2017/Decreto/D9057.htm\#art24. Acesso em: 30 de outubro de 2017.

BUCCI, Maria Paula Dallari Bucci. O conceito de política pública em direito. In: BUCCI, Maria Paula Dallari. Políticas públicas: reflexões sobre o conceito jurídico. São Paulo: Saraiva, 2006.

CAGGIANO, Mônica H.S. A educação: direito fundamental. In: RANIERI, Nina B. S. (Coord.); RIGHETTI, Sabine (Org.). Direito à educação: aspectos constitucionais. São Paulo: EDUSP, 2009.

CARNELUTTI, Francesco. As Misérias do Processo Penal. 1. ed. Campinas: Russell, 2008. 
DUARTE, Clarice Seixas. Direito público subjetivo e políticas educacionais. In: BUCCI, Maria Paula Dallari. Políticas públicas: reflexões sobre o conceito jurídico. São Paulo: Saraiva, 2006.

ESPÍNDOLA, Rui Samuel. Conceito de Princípios Constitucionais. 2. ed. São Paulo: Revista dos Tribunais, 2002.

FOUCAULT, Michel. Vigiar e punir. 41. ed. Petrópolis: Vozes, 2014.

FREITAS, Pedro Ferreira de; MOTTA, Ivan Dias da. O direito à educação como direito da personalidade e mínimo existencial. Revista Jurídica do CESUCA, Cachoeirinha-RS, v.3, n. 6, dez/2015. Disponível em: http://www.egov.ufsc.br:8080/portal/conteudo/o-direito-\%C3\%A0educa\%C3\%A7\%C3\%A3o-como-direito-da-personalidade-e-m\%C3\%ADnimo-existencial . Acesso em: 08 de dezembro de 2016.

MORAES, Alexandre. Constituição do Brasil Interpretação e Legislação Constitucional. São Paulo: Jurídico Atlas, 2003.

MOTTA, Ivan Dias da; LOPES, Mariane Helena. O sistema de cotas sociais para ingresso na universidade pública. Encontro Nacional do CONPEDI, 20, 2011. Belo Horizonte, MG. Anais eletrônicos do XX Congresso Brasileiro do CONPEDI. Florianópolis: Fundação Boiteux, 2011, p. 4341. Disponível em: http://www.publicadireito.com.br/artigos/?cod=9aa70957fde5ac24 . Acesso em: 08 de dezembro de 2016.

MOTTA, Ivan Dias da; RICHETTI, Tatiana. Da necessidade de efetivação do direito à educação por meio de políticas públicas. XXII Encontro Nacional do CONPEDI. Anais eletrônicos do XXII Congresso Nacional do CONPEDI. Curitiba, 2013, p. 246-268. Disponível em: http://www.publicadireito.com.br/artigos/?cod=9aa70957fde5ac24 . Acesso em: 08 de dezembro de 2016.

NETO, Eurico Bitencourt. O direito ao mínimo para uma vida digna. Porto Alegre: Livraria do Advogado Editora, 2010.

PEREIRA, Potyara A.P. Necessidades Humanas: subsídios à crítica dos mínimos sociais. São Paulo: Cortez, 2011.

PIOVESAN, Flávia. Temas de direitos humanos. 3. ed. São Paulo: Saraiva, 2009.

RIZZI, Ester; GONZALEZ, Marina; XIMENES, Salomão. Direito Humano à Educação. 2. ed. rev. e atual., 2011. Disponível em: http://www.direitoaeducacao.org.br/wpcontent/uploads/2011/12/manual_dhaaeducacao_2011.pdf . Acesso em: 08 de dezembro de 2016.

SARLET, Ingo Wolfgang. Dignidade da Pessoa Humana e Direitos Fundamentais na Constituição de 1988. Porto Alegre: Livraria do Advogado, 2001.

SILVA, Rogério Luiz Nery da; MASSON, Daiane Garcia. O Plano de Desenvolvimento da Educação como Política Pública de Efetivação do Direito Fundamental Social à Educação. XXIV Encontro Nacional do CONPEDI-UFS. Direito, Educação e Metodologias do Conhecimento. Florianópolis, 2015. Disponível em: http://www.conpedi.org.br/publicacoes/c178h0tg/017e0bex . Acesso em: 08 de dezembro de 2016. 